Strengthening patient-centred communication in rural

Ugandan health centres:

A theory-driven evaluation

within a cluster randomized trial
Evaluation 2014, Vol. 20(4) 47I-49।

(C) The Author(s) 2014 Reprints and permissions: sagepub.co.uk/journalsPermissions.nav DOI: $10.1|77 /| 3563890|455| 484$ evi.sagepub.com

\title{
Susan Nayiga
}

Infectious Disease Research Collaboration, Uganda

\section{Deborah DiLiberto}

London School of Hygiene \& Tropical Medicine, UK

\section{Lilian Taaka and Christine Nabirye}

Infectious Disease Research Collaboration, Uganda

\author{
Ane Haaland \\ University of Oslo, Norway
}

\section{Sarah G. Staedke and Clare I. R. Chandler \\ London School of Hygiene \& Tropical Medicine, UK}

\begin{abstract}
This article describes a theory-driven evaluation of one component of an intervention to improve the quality of health care at Ugandan public health centres. Patient-centred services have been advocated widely, but such approaches have received little attention in Africa. A cluster randomized trial is evaluating population-level outcomes of an intervention with multiple components, including 'patient-centred services.' A process evaluation was designed within this trial to articulate and evaluate the implementation and programme theories of the intervention. This article evaluates one hypothesized mechanism of change within the programme theory: the impact of the Patient Centred Services component on health-worker communication. The
\end{abstract}


theory-driven approach extended to evaluation of the outcome measures. The study found that the proximal outcome of patient-centred communication was rated 10 percent higher $(p<0.008)$ by care seekers consulting with the health workers who were at the intervention health centres compared with those at control health centres. This finding will strengthen interpretation of more distal trial outcomes.

\section{Keywords}

Africa, complex intervention, patient centred communication, quality of health care, theorydriven evaluation

\section{Introduction}

The quality of health care provided to patients in low-resource settings such as many African health centres is frequently reported to be poor (World Health Organisation, 2005). This has negative effects on uptake of services by community members (D'Ambruoso et al., 2005) and has been reported to result in failure to earn a population's trust, leading clients to seek alternative sources of care (Brown et al., 1993), or to discontinue care (Hall et al., 1993). By contrast, perceptions and experiences of good quality services, including inter-personal attributes, have been found to increase access to care (Mbaruku and Bergstrom, 1995) and demand for services (El Arifeen et al., 2004; McPake, 1993; Wouters, 1991). Satisfied patients may be more likely to adhere to treatment and to maintain a continuing relationship with the health worker (Deyo and Inui, 1980), and loyalty to a clinic (Vera, 1993), resulting in a better medical prognosis, presuming good technical quality of care (Williams, 1994). Meeting a population's expectations for provider services is now seen as central to health system performance (World Health Organisation, 2000), and improved performance central to improving health, especially for maternal and child health outcomes (United Nations, 2010).

In western settings, a 'patient-centred' approach to health care has been increasingly advocated for, as a means to provide high-quality care that addresses patient needs more broadly than 'disease centred' or 'doctor centred' approaches (Balint, 1963; Mead and Bower, 2000). A core focus of the patient-centred approach has been on communication, with interventions to improve interactions stemming from a patient-centred philosophy now common within pre-service and in-service curricula across a range of health care providers (Stewart, 2001). However, evidence for the best methods to achieve patient-centred communication remains weak. A systematic review has suggested that training in patient centredness can have a positive impact on communication quality and on patient satisfaction, although the nature of training was heterogeneous and impact on healthcare use and health outcomes could not be established (Lewin et al., 2001). Interventions that incorporate 'mindfulness' or self-reflection may also be effective in improving communication and health-worker attitudes (Fonn et al., 2001; Krasner et al., 2009) although evidence of the most effective strategies for teaching and learning reflection remains weak (Mann et al., 2009). The need for more rigorous evaluations of patient-centred interventions has been identified, with calls for randomized trial designs and assessment of outcomes that are meaningful to patients (Lewin et al., 2001).

The potential for patient-centred approaches to improve quality of health care in Africa has received little attention. It cannot be assumed that this philosophy 
can be simply transferred from the context in which it was developed, in countries with very different histories and structures of biomedicine, to African health system contexts (Blaise and Kegels, 2004). However, research into patient expectations, preferences and satisfaction with care suggests that interpersonal interactions with health care providers are of central importance across different cultural settings including in Africa (Kizito et al., 2012) and research in Uganda has identified patient-centredness as an aspiration for both health workers and community members for public health facilities (Chandler et al., 2013a). A Patient Centred Services (PCS) component was developed as part of a wider intervention ('PRIME') that aims to improve the quality of health care at public health facilities in rural Uganda. The PCS package is based on patient-centred philosophies adapted to the local setting, and consists of a series of five half-day interactive workshops supported by five take-home selfreflection tasks. The other components of the PRIME intervention were workshops in fever case management (FCM) and in health centre management (HCM), as well as support for supplies of diagnostic tests and drugs for malaria.

Theory-driven evaluations aim to explicate theories or models of given interventions and use this to guide and strengthen evaluation questions and analysis (Coryn et al., 2011). Evaluation practitioners have identified the need to articulate and evaluate the 'implementation theory' or 'action model' of the intervention itself (Chen, 2005; Weiss, 1998) as well as the 'programme theory' or 'change model' (Chen, 2005; Weiss, 1998) of the intended pathway between the intervention and measured outcomes. The documentation of the former, particularly in terms of fidelity and dose received, has become more commonplace. The drawing of logic models is recommended to depict the latter and to guide evaluation activities (Blamey et al., 2013). Methods for the evaluation of intended pathways of change, however, remain diverse. The testing of pre-specified hypotheses is proposed to improve assessment of plausibility that outcomes are attributable to interventions, particularly when composed of multiple components (Bonell et al., 2012), rather than to other factors or a different mechanism triggered by the intervention (Habicht et al., 1999; Webster et al., 2010). We propose that testing pre-specified hypotheses within an intended pathway of change will enable consideration that broader outcomes are attributable to particular aspects of an intervention.

This article presents an evaluation of the impact of the PCS component of the PRIME intervention on the patient centredness of communication of health workers with care seekers, compared with standard care facilities which did not receive any aspect of the PRIME intervention. Here we aim to establish the plausibility of the proposed mechanism of effect of the PCS component of the intervention on a proximal outcome measure - communication - prior to further analyses of the wider impact of the PRIME intervention on malaria management, patient attendance and population-level health outcomes through the main cluster randomized trial.

\section{Study setting}

We carried out this intervention trial at 20 health facilities in Tororo district, Eastern Uganda. Our baseline census showed the study area to be poor, with the mortality rate in children under five years estimated at 11 percent, or 110 deaths per 1000 live births. Fifteen of the health centres serving the area are small, with no in-patient facilities or laboratories, and are typically run by 1-2 nurses or nursing assistants, serving approximately 40 patients per day. Five of the health facilities are larger, with small wards and semi-functioning laboratories and 5-10 health 
workers serving approximately 50 patients per day. Recently, local public health facilities have been plagued by shortages in drugs and equipment, with low levels of staff motivation. Our formative research suggested community members perceived quality of care to vary depending upon supplies and health-worker attitudes. Both health workers and care seekers aspired to better quality of services, including 'patient centredness of services' - the quality of the way services are provided to patients, including interpersonal interactions, particularly with patients from different backgrounds. The formative research suggested that individual health-worker priorities, situated within the challenges of strong hierarchies with other health workers and politicians plus the opportunities presented by their status in relation to patients, appeared to undermine motivation to show respect for patients and provide quality services (Chandler et al., 2013a).

\section{Intervention}

Following reporting recommendations of the WIDER group (www.interventiondesign.co.uk) and others (Glasziou et al., 2010; Michie et al., 2009), we present a detailed description of the intervention and its theoretical rationale. We explicate the implementation theory underlying the intervention and the programme theory as a series of hypotheses in the pathway of change to the desired outcomes of the intervention. In this article, we focus on describing the PCS component of the PRIME intervention. The wider intervention and process of its design is described in detail elsewhere (DiLiberto et al., in preparation). We summarize the delivery of the PCS intervention in practice.

\section{Implementation theory}

The objectives for the PCS component of the PRIME intervention were informed by our formative research and are listed as topics and learning outcomes in Box 1. Figure 1 represents the project's implementation theory of health-worker behaviour change for the intervention, conceived as cognitive, emotional and social, and occurring in a community of practice (Mann, 2011; Wenger, 1998) and supported by physical resources. To stimulate this process for the PCS component of the intervention, a series of five workshops was designed, with each based on a six-step learning process, drawn from adult learning theory (Knowles, 1998; Kolb, 1984), experience-based learning techniques (Van Weel-Baumbarten, 2010) and self-reflection to stimulate purposeful critical analysis of knowledge and experience (Schön, 1983), enable practitioners to engage and deal with their emotions (Lewin, 1951) and develop appreciation and respect for patients (Branch, 2006). The self-reflection tasks were adapted from tasks developed (by $\mathrm{AH}$ ) and tested in a number of other health care settings (Haaland et al., 2006, 2007).

\section{Programme theory}

We drew out hypotheses underlying the PRIME intervention's intended pathway of change. The PRIME intervention, if delivered through respectful, supportive interactions with intervention facilitators, intended to stimulate a process of change that leads to provision of more patient-centred care. The intervention should have proximal impacts on the quality of interactions with patients, resulting in better patient outcomes and appeal of the health facility as well 
Box I. Objectives of the PCS intervention.

\begin{tabular}{|c|c|c|}
\hline \multirow[t]{2}{*}{ Module } & \multirow[t]{2}{*}{ Topic } & \multirow{2}{*}{$\begin{array}{l}\text { Learning outcomes } \\
\text { By the end of this module, participants should be } \\
\text { able to: }\end{array}$} \\
\hline & & \\
\hline \multirow{3}{*}{$\begin{array}{l}\text { PCS } 00 \\
\text { Introduction to } \\
\text { PCS and SOAs }\end{array}$} & $\begin{array}{l}\text { Thinking about my role } \\
\text { as a health worker }\end{array}$ & - Identify their own motivations for work. \\
\hline & Introduction to PCS & $\begin{array}{l}\text { - Understand the meaning and importance of } \\
\text { providing patient-centred services. }\end{array}$ \\
\hline & $\begin{array}{l}\text { Introduction to Self } \\
\text { Observation Activities }\end{array}$ & $\begin{array}{l}\text { - Start developing self-awareness through self- } \\
\text { observation activities. }\end{array}$ \\
\hline \multirow[t]{2}{*}{$\begin{array}{l}\text { PCS } 0 \text { I } \\
\text { Communication } \\
\text { Skills Part I }\end{array}$} & Building Rapport & $\begin{array}{l}\text { - Recognize the impact of non-verbal and verbal } \\
\text { behaviour on the patient and consultation } \\
\text { outcome. } \\
\text { - Strengthen non-verbal and verbal skills in building } \\
\text { rapport. } \\
\text { - Recognize that we think of different people in } \\
\text { different ways, and this affects how we behave } \\
\text { towards them. } \\
\text { - Understand that respect is a core value for how } \\
\text { we can put patients at ease. } \\
\text { - Strengthen skills to show respect to patients. }\end{array}$ \\
\hline & Active listening & $\begin{array}{l}\text { - Strengthen skills in self-reflection. } \\
\text { - Strengthen non-verbal and verbal skills in active } \\
\text { listening. } \\
\text { - Recognize the consequences of listening well, } \\
\text { and less well, on the patient and consultation } \\
\text { outcome. } \\
\text { - Identify ways to listen actively in spite of busy } \\
\text { work environments. }\end{array}$ \\
\hline \multirow[t]{2}{*}{$\begin{array}{l}\text { PCS } 02 \\
\text { Communication } \\
\text { Skills Part } 2\end{array}$} & Asking good questions & $\begin{array}{l}\text { - Understand the importance of getting good } \\
\text { information. } \\
\text { - Be aware of the way and consequences of how } \\
\text { they ask questions. } \\
\text { - Know how to formulate open questions. } \\
\text { - Ask questions without showing judgement. }\end{array}$ \\
\hline & $\begin{array}{l}\text { Giving good } \\
\text { information }\end{array}$ & $\begin{array}{l}\text { - Understand the importance of giving good } \\
\text { information. } \\
\text { - Be aware of the way and consequences of how } \\
\text { they give information. } \\
\text { - Know how to give good information to patients. } \\
\text { - Understand how to empower patients to follow } \\
\text { advice. }\end{array}$ \\
\hline $\begin{array}{l}\text { PCS } 03 \text { Building } \\
\text { a positive work } \\
\text { environment }\end{array}$ & $\begin{array}{l}\text { Health Centre } \\
\text { Management Changes }\end{array}$ & $\begin{array}{l}\text { - Recognize their challenges at work. } \\
\text { Know about planned Health Centre Management } \\
\text { changes. } \\
\text { - Know their role in Health Centre Management } \\
\text { changes. }\end{array}$ \\
\hline
\end{tabular}


Box I. (Continued)

\begin{tabular}{|c|c|c|}
\hline \multirow[t]{2}{*}{ Module } & \multirow[t]{2}{*}{ Topic } & Learning outcomes \\
\hline & & $\begin{array}{l}\text { By the end of this module, participants should be } \\
\text { able to: }\end{array}$ \\
\hline \multirow{3}{*}{$\begin{array}{l}\text { PCS } 04 \\
\text { Improving the } \\
\text { Patient Visit }\end{array}$} & $\begin{array}{l}\text { Dealing with stress at } \\
\text { work }\end{array}$ & $\begin{array}{l}\text { - To recognize stress by how we feel and behave. } \\
\text { - To understand the effect of automatic reactions } \\
\text { on us and others. } \\
\text { - To know how to 'step back' and stop automatic } \\
\text { reactions. } \\
\text { - To carry a picture of best practice in dealing with } \\
\text { difficult patients and situations. }\end{array}$ \\
\hline & Communication Review & $\begin{array}{l}\text { Become aware of ways to invite their patients and } \\
\text { colleagues to co-operate and the impact of doing } \\
\text { this. }\end{array}$ \\
\hline & $\begin{array}{l}\text { Patient Welcome and } \\
\text { Orientation }\end{array}$ & $\begin{array}{l}\text { - Recognize that we all have different perspectives, } \\
\text { including as health workers and patients. } \\
\text { - Put themselves into the shoes of a patient } \\
\text { approaching a health centre as an organization } \\
\text { with unspoken 'rules'. } \\
\text { - Explore reasons why patients have to wait long, } \\
\text { and develop strategies that meet health workers' } \\
\text { as well as patients' needs better. } \\
\text { - Implement strategies to improve the welcome of } \\
\text { - Implents at health centres. } \\
\text { - Implent strategies to improve the orientation } \\
\text { fairly. }\end{array}$ \\
\hline
\end{tabular}

as higher satisfaction of health workers with their work. This intended process of change is depicted in Figure 2. The changes at the health facility, including more patient-centred services, should attract patients who previously may have been afraid or reluctant to attend, thereby increasing access to prompt, effective treatment, particularly for malaria, the highest burden disease in the area. In turn, this is hypothesized to have an impact on health indicators in the local population, particularly for young children (for a visual representation see Supplementary Figure). These latter outcomes are being assessed in the main PRIME cluster randomized trial.

\section{Intervention delivery}

The PRIME intervention workshops took place from May to July 2011. The five PCS modules were carried out through weekly face-to-face afternoon sessions in small groups of between seven and 14 participants at a local hall. Two sessions of PCS workshops were held to encourage participation of all health workers. Participants were provided with transport refunds for their attendance in addition to refreshments. The PCS workshops were facilitated by three members of the PRIME research team with backgrounds as medical doctors and limited 


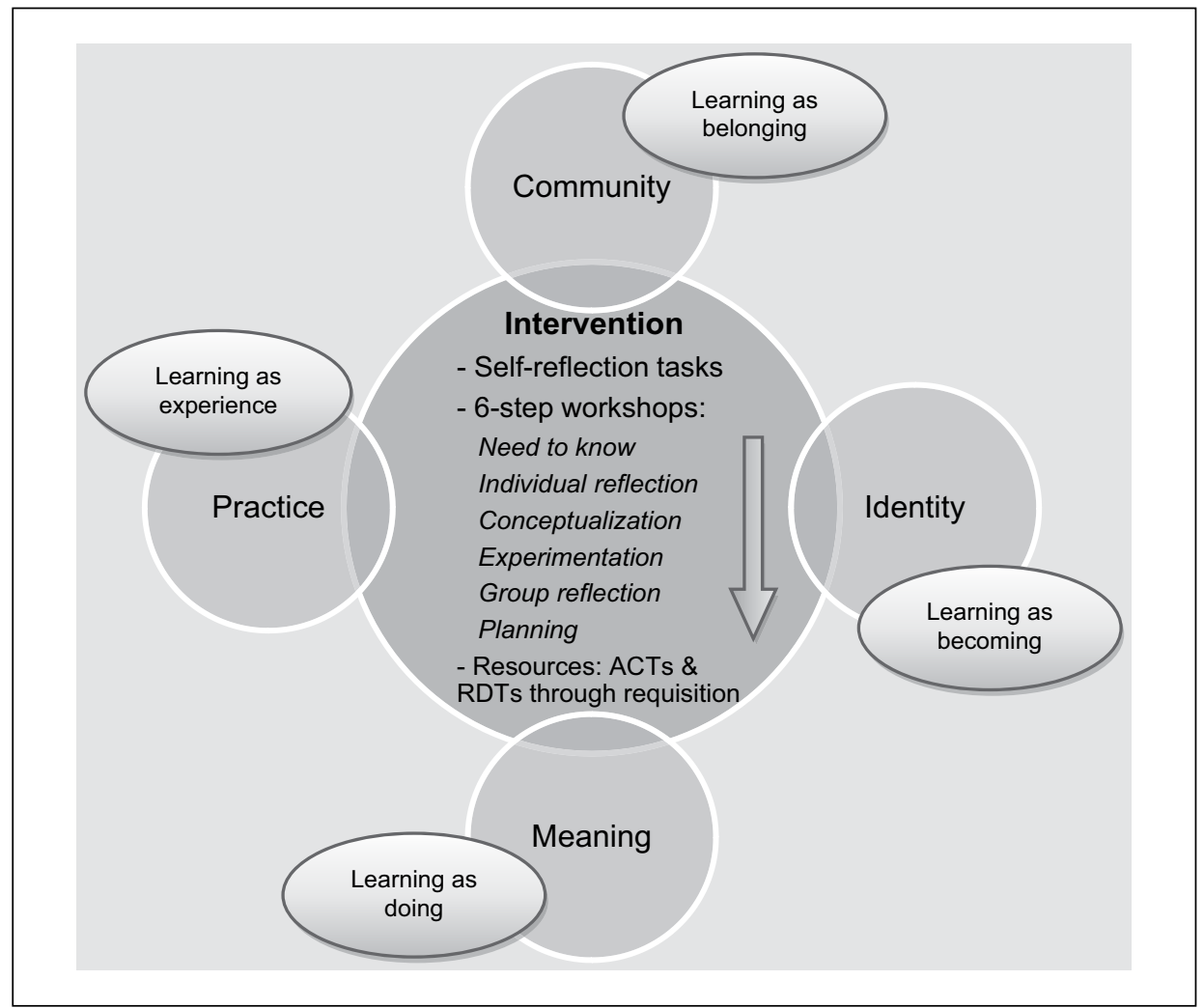

Figure I. Implementation theory of change for PRIME intervention at health centres.

experience in interactive training methods, following a precedent of other Ministry of Health endorsed health-worker training in Uganda (Ssekabira et al., 2008). Two facilitators attended a two-day workshop on experience-based learning methods (led by $\mathrm{AH}$ ) in Kenya, where a health communication training project was ongoing. All facilitators completed a series of selfreflection tasks (developed by $\mathrm{AH}$ ) in line with those to be conducted in the PCS intervention. In addition, all facilitators attended a one-day orientation on the PRIME training approach (led by CIRC), in line with an 'introduction for trainers' manual (available from the authors). Facilitators also helped to pilot each module and received feedback for each of the workshops. A trainer manual was designed for each module to guide the format and activities of workshops, and participants also received a manual for each workshop to follow activities and to take home. Manuals are available at: http://www.actconsortium.org/publications.php/12/ prime-trainer-and-learner-manuals. Overall contact time for health workers attending PCS workshops was approximately 19 hours.

Participants were encouraged to carry out self-reflection to support their learning in the PCS workshops. They were given 'tasks' to complete each week, for example to observe how they listened to their patients, and were encouraged to feed back and discuss their reflections with colleagues at the next workshop. Each task was expected to take around one hour over the duration of the week. Standard care facilities received no PCS workshops or self-reflection tasks or other components of the PRIME intervention. 

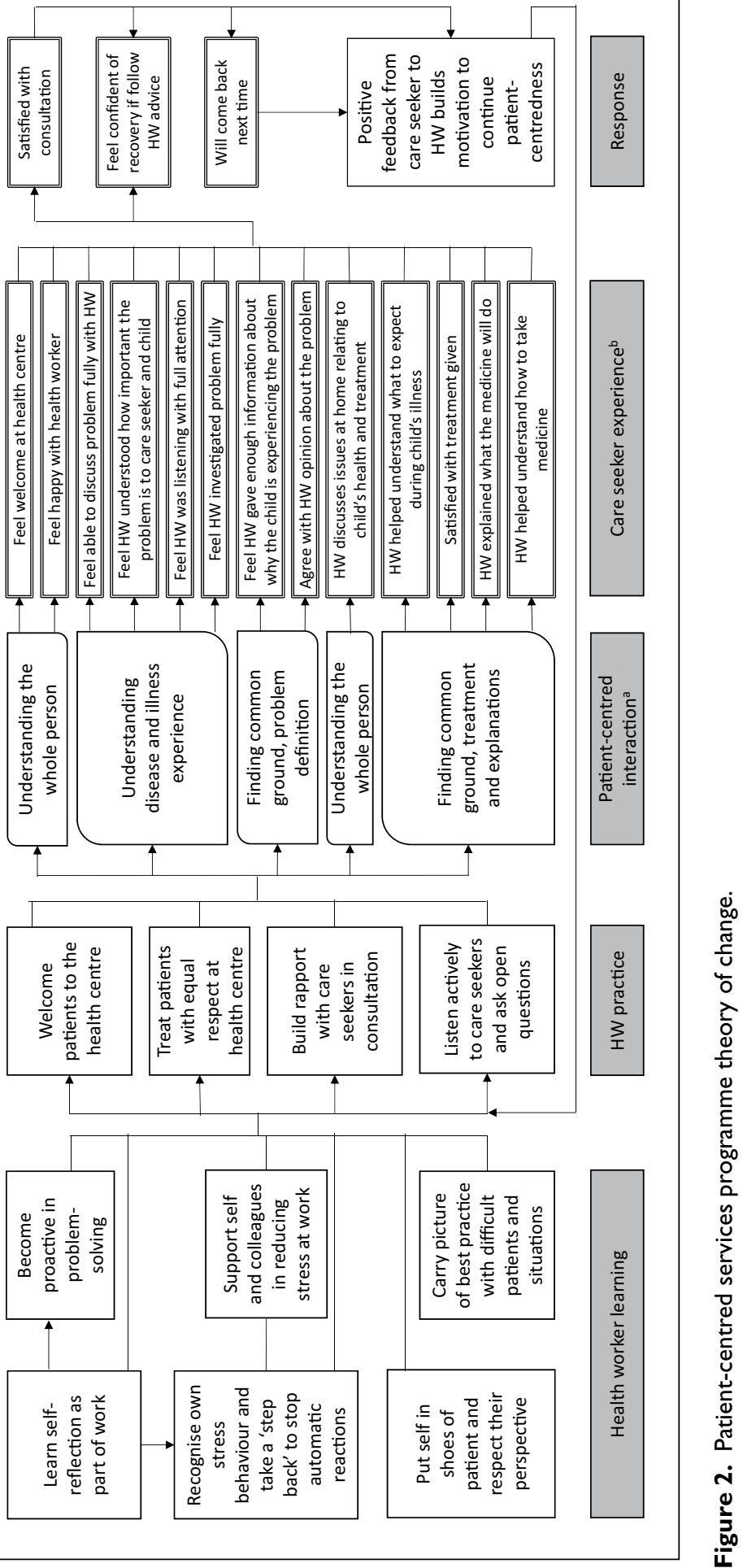


\section{Methods}

\section{Objectives}

The objective of the analysis presented in this article is to test whether the PCS component of the PRIME intervention had an immediate impact on patient centredness of health-worker communication. This tests one hypothesized mechanism of effect in the intervention's intended pathway of change.

\section{Study design}

Following critiques of the limitations of randomized trials to understand 'what works' in complex interventions (Cartwright, 2011; English et al., 2011; Hawe et al., 2004), we followed recommendations of the Medical Research Council and others (MRC, 2008; Oakley et al., 2006) to nest a process evaluation to assess fidelity and mechanisms of effect within a cluster randomized trial design. We used a logic model to depict assumed mechanisms of change from the inputs of the intervention to the outcomes measured at the population level in the main trial. The process evaluation documents fidelity of the intervention as well as assessing mechanisms of effect through quantitative indicators and qualitative methods to understand how the intervention is enacted in practice (Chandler et al., 2013b). In this article, we focus on the proximal effect of the PCS intervention, utilising the wider cluster randomized trial design (Staedke et al., 2013) to evaluate the intervention package's impact on health-worker communication.

\section{Health centre sample size and randomization}

A sample size of 20 clusters was determined for the main trial's primary outcome, prevalence of anaemia in children under five, which was assessed in a cross-sectional survey. Assuming a coefficient of variation between clusters of 0.2 , anaemia prevalence in the control arm of 65 percent, and 200 children under five surveyed in each cluster, 10 clusters per arm would give 80 percent power to detect an absolute difference of 17 percent in anaemia prevalence, at significance level 5 percent. The 20 health centres were allocated to intervention or standard care using a stratified, restricted randomization, based on operational level (II or III), sub-county and size of catchment area. Researchers and health workers were not masked to the intervention. For full details see Staedke et al. (2013).

\section{Outcomes and measurement}

The outcome of interest in this analysis is patient centredness of health-worker communication. This can be assessed in different ways, including by direct observation, coding of video or audio recordings of consultations, and interviews or self-filled questionnaires (Kruijver et al., 2000; Stewart, 1995). Validation of methods for evaluating patient-centredness or healthworker communication has mostly taken place in Northern settings (Hudon et al., 2011), with such evaluations rare in Africa (Labhardt et al., 2010). We undertook two different methods of assessment in our evaluation: interviews with care seekers on exit, to gain an insight into their assessment of the health worker's quality of communication, and audio recordings of interactions between health workers and care seekers. A rating scheme was used to assign a quantitative score of health-worker communication for each method. 
We based the rating schemes for both methods on the primary components of patient-centred communication identified by the Patient-Doctor Communication Group in Canada (Stewart et al., 1995), and widely used in western settings: Component I 'exploring both the disease and the illness experience,' represents the physician's exploration not only of the disease process, through history taking and physical examination but also their active engagement with the patient's world, to understand their unique illness experience'; Component II, 'understanding the whole person', represents the way the physician integrates these concepts of disease and illness with an understanding of the whole person, including an awareness of the patient's position in the life cycle and context within which they live, such as family, work and culture; Component III 'finding common ground,' Consists of the physician defining the problem together with the patient, establishing goals of treatment or management and identifying the roles to be assumed by each. These three components can be equated to Mead and Bower's (2000) key concepts of 'patient-as-person', 'biopsychosocial perspective', and 'sharing power and responsibility' (Hudon et al., 2011).

The exit interviews with care seekers followed a structured questionnaire format, representing the three components of communication described above, with Component III broken down into 'problem definition' and 'treatment and explanations' as two domains, and the addition of one domain of overall satisfaction with the consultation. We adapted the questions from Stewart et al.'s (2004) patient perceptions of care questionnaire through a process of translation and pretesting with care seekers at health facilities nearby to our study area. Our final questionnaire, detailing the components and domains within each, together with our scoring system, can be found in the Supplementary File. Figure 2 shows how the domains for the communication assessments through both methods relate to each other and to the intervention's learning outcomes.

The audio recordings were rated using the Measurement of Patient Centred Communication scoring system (Brown et al., 2001). This involves a detailed protocol whereby coders categorize statements from the patient that are pertinent to the patient-centred method and assess the physician's response. An overall score is generated as a composite of the responses given to the relevant utterances of patients. Due to the complexity of this rating system, we chose not to adapt it, but rather sought to assess its application in this setting. Two members of the team ( $\mathrm{SN}$ and $\mathrm{CN}$ ) coded each interaction. Any differences in ratings were reviewed by both raters together and a score agreed or taken to a third party (LT or CIRC) for a final decision.

\section{Study sample}

We aimed to include at least one health worker from all 10 intervention and 10 standard care health facilities, and to recruit the same health worker at baseline and follow-up where possible for increased comparability given anticipated between-health-worker variation. The most senior health worker working at the time of recruitment was invited to participate on the basis that they would see the most patients in this context. A communication score was calculated from exit interviews and audio-recorded interactions for each of between three and five care seekers per health worker, the minimum usually required within a cluster for a multi-level analysis. Eligibility criteria for care seekers were those seeking care for a child under five years with a fever but no sign of severe disease. The target sample size for each time point was 20 health-worker and 100 care-seeker exit interviews and audio-recorded interactions across both study arms. We aimed to include the same health workers at each time point, but assumed care seekers would be different between time points. 


\section{Data collection}

We assessed the patient centredness of health-worker communication at baseline and following completion of the workshops. All health facilities in the trial were informed in advance about evaluation activities. A team of two researchers visited each health centre for the communication assessment, seeking consent from the health worker on duty to audio-record consultations and screening care seekers for participation in the audio-recorded interactions and exit interviews. Written informed consent was sought from care seekers who were eligible and agreed to participate, and demographic information about the patients was documented. When the care seekers entered the consulting room, a digital audio recorder was switched on and the researcher left the room. On exit, one researcher switched off the recorder and another invited the care seeker for a brief interview.

\section{Data analysis}

Analyses were carried out in STATA version 11 (College Station, TX, USA). Linear regression was used to compare scores between the study arms and to assess health-worker and careseeker factors potentially affecting outcomes. Where exposure variables were ordered, such as age group, a test for trend was carried out. Clustering was assessed through the intra-class correlation coefficient at baseline and was adjusted for in analysis using a random effects linear regression model. Baseline outcome scores were calculated at the health-centre level and adjusted for in the multivariable models by including it as a covariate. Factors found to be significantly associated with the outcome variables $(p<0.10)$ were included in the multivariable models in turn, and were removed if no longer significant.

The main analysis was carried out on an intention-to-treat basis, comparing all health workers allocated to the intervention with those from standard care facilities. In order to assess the plausibility of effects on communication being due to the PCS intervention, a plausibility analysis using a 'dose received' principle was carried out comparing those who attended all five PCS workshops with those who attended fewer or none and comparing this with attendance at workshops for other components of the intervention that were not intended to affect health-worker communication.

\section{Ethics}

The trial and process evaluation studies were approved by the Ugandan National Council for Science and Technology (UNCST Refs HS794 and HS864), the Makerere University School of Medicine Research \& Ethics Committee (SOMREC Refs 2010-108 and 2001-103), and the London School of Hygiene and Tropical Medicine Ethics Committee (LSHTM Refs 5779 and 5831). The trial was additionally approved by the University of California San Francisco Committee on Human Research (UCSF CHR Ref 006160). Sponsorship and insurance was provided by the LSHTM's Clinical Trials Sub-Committee (Ref QA292).

\section{Results}

\section{Enrolment}

Figure 3 shows the flow of participants through the trial who contributed to the communication evaluation outcome. Measurement of this proximal outcome took place at baseline in 
April-May 2011 and at follow-up in July 2011. In all, 20 health facilities were randomly assigned to intervention and standard care arms, with no refusals to participate. A total of 26 health care workers and 213 health care seekers participated in the evaluation, with approximately even numbers between the arms and the two time points. All invited health workers and care seekers agreed to participate. Audio-recordings were made for consultations of 22 health workers with 100 care seekers at baseline and 24 health workers with 113 care seekers at follow-up. Of these care seekers, 97 at baseline and 108 at follow-up participated in exit interviews. A total of eight care seekers were lost before the exit interview.

\section{Participant characteristics}

We present characteristics of both health workers and care seekers including those participating at baseline at follow-up, since the participants varied between time points, in Supplementary File 2 (Tables A and B). Most health workers held a certificate rather than diploma or degree, were a median of 37 years of age (range 25-57) and had been health workers for around 10 years (range 2-35 years). Two-thirds were originally from the area, and 73 percent reported speaking Japhadhola, Swahili and another local language. Characteristics were similar between the two arms, although we were able to include more in-charges (with responsibility for health centres) from the standard care facilities in the assessments. Almost all care seekers were women, and two-thirds were under 30 years of age. Over half $(58 \%)$ of the care seekers had attended primary school, but a further 25 percent had had no education. The majority $(85 \%)$ reported their primary activity as a farmer. Nearly all $(93 \%)$ had been to the health centre before. Patients were all children under five years, with most under 18 months. There was little difference between the study arms in care seeker or patient characteristics. All consultations were conducted in the local Japadhola language, although only 65 percent of health workers reported to be fluent speakers.

Clustering of outcomes as measured through both the exit interviews and the audiorecorded interactions was observed at the health-worker, and by extension, health-facility levels. The intraclass correlation coefficients, calculated at baseline, are shown in Supplementary File 2 (Table C). All analyses presented are adjusted for clustering using a random effects model.

\section{Crude outcomes}

Care-seeker exit interview scores. Before the intervention, the overall scores from care seekers at exit were similar in the intervention arm (mean of 76.1\%) and the standard care arm (mean of $80.3 \%, p=0.23$ ). After the intervention was initiated and workshops complete, a 9.4 percent increase in scores was observed at intervention health centres compared with a decrease of 4.7 percent in the standard care arm. A crude comparison of scores between the two arms at follow-up showed a statistically significantly higher score in the intervention arm, at 85.5 percent compared with 75.6 percent in the standard care health facilities $(p=0.02)$. Analysis of training attended suggested this association was related to attendance at the PCS rather than the other modules that were part of the overall intervention (Table 1). A breakdown of domains within the care-seeker exit interview score showed significantly higher scores in the intervention arm across each of the components except for the part of Component III on 'problem definition,' which was very high in both arms. 


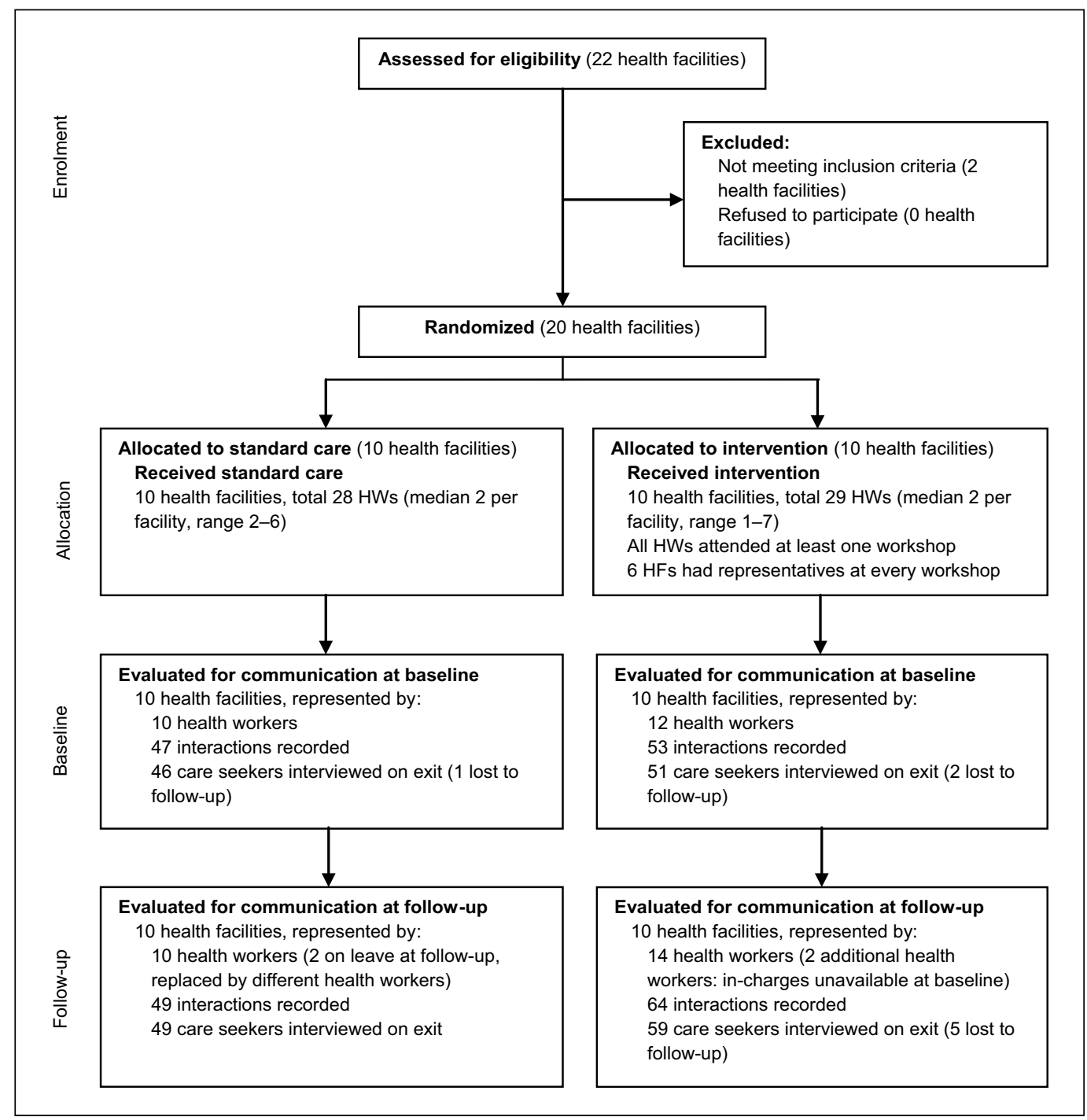

Figure 3. Flow of participants and clusters through the trial.

Audio-recorded interaction scores. The scores of audio-recorded interactions using the MPCC scoring system were very low at baseline and follow-up in both arms. Baseline scores were 13 percent in the standard care and 12.4 percent in the intervention arm $(p=0.51)$ and at followup, crude scores were 15.9 and $15.7(p=0.74)$. A breakdown of the three components of the audio-recorded interaction scores showed a small but statistically significantly higher mean score in the intervention arm compared with the standard care arm (3.4 versus $2.1, p=0.04$ ) for Component I of health-worker communication, 'exploring the disease and illness experience.' This seemed to be driven primarily by higher scores for the way symptoms and the reason for visit were explored, as well as following up on care-seeker prompts and ideas, since no health workers explored the care seeker's feelings or expectations from the consultation in any arm or time point. Scores for 'understanding the whole person', Component II of the 
Table I. Communication scores by study arm at baseline, post-intervention and dose received for each measurement method.

\begin{tabular}{|c|c|c|c|c|c|}
\hline & \multirow[t]{2}{*}{ Number $(n)^{\mathrm{a}}$} & \multicolumn{2}{|l|}{$\begin{array}{l}\text { Care-seeker } \\
\text { assessment }\end{array}$} & \multicolumn{2}{|c|}{$\begin{array}{l}\text { Audio-recorded interaction } \\
\text { assessment }\end{array}$} \\
\hline & & $\begin{array}{l}\text { Exit interview } \\
\text { score }\left(95 \% \mathrm{Cl}^{\mathrm{b}} \text { of }\right. \\
\text { difference) }\end{array}$ & $P$-value & $\begin{array}{l}\text { Audio- recorded } \\
\text { interaction score } \\
(95 \% \mathrm{Cl} \text { of difference })\end{array}$ & $P$-value \\
\hline \multicolumn{6}{|l|}{ Baseline } \\
\hline Standard care & 47 & 80.3 & & 13.2 & \\
\hline Intervention & 53 & $76.1(64.3,79.6)$ & 0.29 & $12.4(8.6,14.7)$ & 0.63 \\
\hline \multicolumn{6}{|l|}{ Post-intervention } \\
\hline Standard care & 49 & 75.6 & & 15.9 & \\
\hline Intervention & 64 & $85.5(86.6,100.4)$ & 0.02 & $15.8(14.3,16.9)$ & 0.83 \\
\hline \multicolumn{6}{|c|}{$\begin{array}{l}\text { Dose of PCS received } \\
\text { (modules attended) }\end{array}$} \\
\hline None & 49 & 77.6 & & 15.9 & \\
\hline 1 & 12 & $85.3(81.6,104.4)$ & & $15.7(\mid 3.1,17.8)$ & \\
\hline 2 & 17 & $80.0(71.1,93.7)$ & & $16.3(14.6,18.9)$ & \\
\hline 4 & 10 & 83.1 (75.7, 101.4$)$ & & $15.8(13.2,18.4)$ & \\
\hline 5 & 25 & $89.3(92.2,109.8)$ & $0.0 \mathrm{I}^{\mathrm{c}}$ & $15.5(13.2,16.8)$ & $0.67^{c}$ \\
\hline \multicolumn{6}{|c|}{ Dose of $\mathrm{HCM}$ received } \\
\hline None & 70 & 80.0 & & 15.7 & \\
\hline 1 & 12 & $90.4(86.5,115.1)$ & & $15.6(13.2,18)$ & \\
\hline 2 & 5 & $86.1(73.7,110.7)$ & & $15.9(12.8,19.5)$ & \\
\hline 3 & 26 & $84.4(79.9,97.6)$ & $0.28^{c}$ & $16.3(15.3,18.6)$ & $0.4 I^{c}$ \\
\hline \multicolumn{6}{|c|}{ Dose of FCM received } \\
\hline None & 69 & 80.2 & & 15.9 & \\
\hline Attended & 44 & $84.9(82.0,97.0)$ & 0.23 & $15.8(14.3,17)$ & 0.87 \\
\hline
\end{tabular}

Note: adjusted for clustering at the health-worker level. Between 3-5 patients sampled per health worker.

aFive patients lost between audio-recording and exit interview.

bConfidence Interval.

cTest for trend.

MPCC system, were zero across all interactions. Scores were also low for Component III, 'finding common ground,' because although most interactions addressed 'goals of treatment or management,' the scoring system suggested these were dealt with inadequately, and there were few interactions addressing 'problem definition' or 'response to disagreement,' resulting in low overall scores, with no detectable difference between trial arms.

\section{Factors affecting outcomes}

Univariate analyses (presented in Supplementary File 2, Tables D and E) suggested few characteristics of health workers were associated with the communication scores using either method of measurement. However, scores by both measurement methods were lower for those who had been working as a health worker for a shorter time than five years, although the trend was clearer for the care-seeker scores, which showed a clear increase in communication scores for health workers who had been in the job for a longer time. Few care-seeker characteristics were 
associated with communication scores but care-seeker communication scores were statistically significantly higher when the care seeker was originally from the area. Care seekers were less satisfied with communication when they were unemployed compared with other categories of employment. Care-seeker communication scores were statistically significantly higher for children who were older and male, and lower for children who presented with flu in addition to fever.

\section{Adjusted analyses}

Estimates of effect of the intervention on communication outcomes were adjusted for baseline mean scores for each health centre and for clustering on the health-worker level. Other participant characteristics found to affect outcomes in the univariate analysis were also added to an adjusted model, and were included in the final model only if they remained statistically significantly associated with the outcome. The final adjusted model using the care-seeker communication score is shown in Table 2, showing an overall higher score of 10.0 percent in the intervention compared with the standard care arm $(p=0.008)$, adjusting for an increased score of 10.1 percent amongst care seekers originally from the area $(p=0.006)$. No other covariates were statistically significant in the final model. The final adjusted model using the audiorecorded interaction communication score showed no significant difference between the intervention and standard care arm (Table 2). No covariates were significantly associated with the audio-recorded interaction scores in the final adjusted model.

\section{Plausibility of mechanism of effect}

To assess whether the difference in communication observed using the care-seeker rating method could be plausibly attributed to the PCS intervention's intended mechanism of effect, rather than to other components of the intervention, we undertook a dose-response analysis of workshops attended. All health workers in the intervention arm had attended some of the intervention training: only three of 14 in the intervention arm had attended all nine workshops, and only six had attended all PCS sessions. Univariate analysis suggested communication scores were not statistically significantly higher amongst those who received some or all of the health centre management training or fever case management training compared with those who had attended no or fewer sessions. However, scores were significantly higher for those who had attended all of the PCS workshops. A plausibility analysis based on the dose received, replacing the intention to treat intervention variable with a binary variable of attendance at all PCS workshops, suggests that this component of the intervention played a large role in the higher communication scores in the intervention arm (Table 3).

\section{Discussion}

This evaluation showed patient-centred communication was rated 10 percent higher $(p<$ 0.008 ) by care seekers consulting with health workers who had recently participated in the PRIME intervention compared with those in the standard care arm. Analysis of the dose received suggests this increase may be plausibly attributed to the PCS component of the intervention. The sustainability of this effect, and any impact on patient attendance and population level outcomes will be assessed with data from the main PRIME trial, which is ongoing.

Interventions to improve quality of services in Africa have often focused on commodities and technical skills training, often with limited impacts on practice (Rowe et al., 2005). Our 
Table 2. Final adjusted models of the two measurement methods for communication comparing intervention and control health workers post-intervention.

\begin{tabular}{lll}
\hline & Difference in scores $(95 \% \mathrm{Cl})$ & p-value \\
\hline Care-seeker communication score $^{\mathrm{a}}$ & $42.7(\mathrm{II} .1,74.3)$ & \\
Intervention & $10.0(2.5,16.7)$ & 0.008 \\
Care seeker from the area & $10.1(2.9,17.2)$ & 0.006 \\
Health facility mean score at baseline & $32.3(-5.9,70.6)$ & 0.098 \\
Intra-class correlation coefficient & 0.28 & \\
Audio-recorded observation communication score & & \\
Intervention & $16.1(13.4,19.0)$ & 0.819 \\
Health facility mean score at baseline & $-0.2(-1.5,1.2)$ & 0.843 \\
Intra-class correlation coefficient & $-2.0(-21.6,17.7)$ & \\
\hline
\end{tabular}

Note: models adjust for clustering at health-worker level and mean health facility scores at baseline.

a Mean score in baseline category of each variable (e.g. standard care arm, care seeker not from the area and no difference in health facility mean score compared with baseline).

Table 3. Dose response model of care-seeker communication scores for health workers attending all PCS workshops.

\begin{tabular}{lll}
\hline & Difference in scores $(95 \%$ & P-value \\
& Confidence interval) & \\
\hline Care-seeker communication score & & \\
All 5 PCS workshops attended & $58.4(I I .1,74.3)$ & 0.042 \\
Care seeker from the area & $8.5(0.3,16.7)$ & 0.009 \\
Health facility mean score at baseline & $9.7(2.5,17.0)$ & 0.098 \\
Intra-class correlation coefficient & $16.9(-21.4,55.2)$ & \\
\hline
\end{tabular}

Note: model adjusts for clustering at health-worker level and mean health facility scores at baseline.

a Mean score in baseline category of each variable (i.e. no PCS attended, care seeker not from the area and no difference in health facility mean score compared with baseline).

results suggest that interventions that take a self-reflective approach, with repeated facilitated interactions with communities of practice over time, may have a positive impact on improving interpersonal aspects of care. Our PCS intervention package is clearly described in trainer and learner manuals and could be adapted and/or tested for use in other settings to establish the generalizability of our findings.

Scores of patient-centredness between the two methods tested were markedly different, with the audio recording scores very low overall, with zero ratings in several of the domains. By contrast, questions posed to care seekers relating to the same domains showed that often health workers were perceived to perform well. This contrast may be interpreted as a true difference or measurement error. Patients are often thought to overstate quality of care in exit interviews (Sitzia, 1999), which might account for higher overall scores, and suggest that 'objective' rating should be weighted more highly. However, the range in care-seeker scores and differences between arms suggests they were sensitive to and willing to rate based on differences in healthworker performance, and therefore relative differences should still be of value even if not the absolute scores. We are more inclined to interpret measurement error on the part of the audio recording method, which is subject to analysis based on what is said, rather than what is heard or interpreted (Epstein et al., 2005). Furthermore, scoring systems of interactions are culturally 
specific, based on the expected patterns of speech, for example in 'finding common ground'. Our interpretation is that such rating systems do not travel well cross-culturally and that locally specific modes of assessing interactions would be required, and that direct observations would be most effective in capturing non-verbal communication in context.

We adopted a theory-driven evaluation approach to this nested process evaluation within a wider cluster randomized trial. Such evaluations have been recommended but are uncommon in the literature (Bonell et al., 2012). The wider trial provided an opportunity to test hypotheses explicated as underlying the programme theory using a probability approach. This fitted well with the overall evaluation approach of an RCT, allowing for main trial outcomes to be interpreted and attributed in part to this component of the intervention whilst sharing common language and assumptions. However, this approach of attaining a quantitative measure of patient-centredness, and 'adjusting' for differences between people and contexts through randomization, also bracketed-out the breadth and depth of the realities of health-worker-careseeker relationships, which vary a lot and are context dependent. Alternative approaches to evaluation might include a case-study approach whereby these brackets are removed and variation is explored not through statistics but through a meaning-based interpretation of how patient-centredness may or may not play out in practice. Such approaches are, however, often critiqued as 'biased' and the necessarily subjective approach viewed as a problem by those seeking to distill social worlds to measurable variables (Denzin and Lincon, 2005). Thus, the theory of change based approach to understanding interventions presents a compromise between outcomes-based and process-based perspectives by offering a way to articulate and interrogate often implicit hypotheses of change. But, this compromise takes 'theory' into a positivist epistemology, focusing on reducing and testing, and is hard to connect with and allow emergence of perspectives that recognize values such as 'patient centredness' as socially constructed and therefore differing in meaning for different actors. For evaluation to progress beyond identifying relatively small differences observable through measurable phenomena, our ways of knowing, or epistemological stance, needs to be open to challenge.

\section{Limitations to interpretation}

We recognize limitations in several aspects of this study, including in the measurement methods as mentioned above, sample size, plausibility analysis and replicability of results. We had a relatively small sample size per health worker, with up to five audio-recordings and exit interviews for each health worker at each time point. This could introduce the potential for observer bias, meaning that the absolute values attributed to health-worker performance may be higher than if they were not being observed. This effect should be evenly distributed across the two arms, although it is possible that those who participated in the intervention were familiar with values of the project in terms of communication and performed accordingly. However, health workers were not informed about the measurement method in advance and this was not discussed during the workshops.

While our analysis of dose-received strengthens the plausibility that the PCS package was influential in changing provider practices, we recognize that there is the potential for selection bias amongst the sample of health workers who chose to attend more PCS workshops, perhaps due to higher motivation to perform well, 'incentives' perceived, or for the rare opportunity to attend a workshop as a lower cadre staff member. Scale up of such a programme should also expect varying degrees of interest on the part of those invited to such workshops, with the potential for a diluted effect amongst the wider health-worker population. 
Finally, as with any intervention delivered on a small scale, the replicability of the intervention, and consequently its impact, is limited by the way it was delivered. The trial fell between an efficacy and effectiveness study: while we attempted to control the content and mode of delivery through standardized manuals and training of trainers, health workers were not obliged to participate in any or all workshops. Delivery of learning-based interventions are highly dependent on the characteristics of those delivering the training as well as the dynamics generated by the participants in particular workshops. While our use of medical doctors as trainers mimics the typical situation in Uganda of trainers having some medical background, it is likely that the status of our trainers was elevated from their medical degree and position in a research organization. Any scale-up of this programme would require careful selection and training of trainers in methods and attention to the role this may play in reproducibility of results.

\section{Conclusion}

A theory-driven evaluation approach enabled the explication and testing of programme theory for one of several components of a complex intervention. The PCS intervention, inspired by patientcentred philosophies and tailored to the context of health facilities in rural Uganda, appeared to increase care-seeker ratings of health-worker communication by 10 percent compared with those visiting health workers in the standard care arm. Interpersonal qualities in health care may be improved by such interventions based on self-reflection and facilitated workshops with small groups of peers. The sustainability of this effect, and any impact on patient attendance and population level health outcomes remain to be assessed with data from the ongoing trial. The finding of this proximal level outcome will strengthen interpretation of more distal trial outcomes.

\section{Acknowledgements}

We are grateful to Miriam Kayendeke, Nicholas Wendo, Michael Oketcho and Paul Olowo for their work in the field, to Florence Nankya, Cathy Maiteki and Lucas Othieno for their work as workshop facilitators, to Levi Mugenyi for his work constructing the coding database and to Bonnie Cundill for consultation on statistical methods. We thank the DHO of Tororo District for supporting our research and we thank all the health workers and care seekers who participated in this study.

\section{Funding}

This work was supported by the ACT Consortium through a grant from the Bill and Melinda Gates Foundation to the London School of Hygiene \& Tropical Medicine.

\section{References}

Balint M (1963) The Doctor, his Patient and the Illness. London: Churchill Livingstone.

Blaise P and Kegels G (2004) A realistic approach to the evaluation of the quality management movement in health care systems: a comparison between European and African contexts based on Mintzberg's organizational models. International Journal of Health Planning and Management 19: 337-64.

Blamey AAM, MacMillan F, Fitzsimons CF, et al. (2013) Using programme theory to strengthen research protocol and intervention design within an RCT of a walking intervention. Evaluation 19: 5-23.

Bonell C, Fletcher A, Morton M, et al. (2012) Realist randomised controlled trials: a new approach to evaluating complex public health interventions. Social Science \& Medicine 75: 2299-306.

Branch WT Jr (2006) Viewpoint: teaching respect for patients. Acad Med 81: 463-7.

Brown JB, Stewart MA and Ryan BL (2001) Assessing communication between patients and physicians: the measure of patient-centred communication (MPCC). Working Paper Series, Paper \# 
95-2, 2nd Ed. London, Ontario: Thames Valley Family Practice Research Unit and Centre for Studies in Family Medicine.

Brown LD, Franco LM, Rafeh N, et al. (1993) Quality assurance of health care in developing countries. Bethesda, MD: Quality Assurance Project. URL (consulted 5 April 2012): http://pdf.usaid.gov/ pdf_docs/Pnabq044.pdf

Cartwright N (2011) A philosopher's view of the long road from RCTs to effectiveness. Lancet 377: $1400-1$.

Chandler CI, Kizito J, Taaka L, et al. (2013a) Aspirations for quality health care in Uganda: how do we get there? Hum Resour Health 11: 13.

Chandler CI, Diliberto D, Nayiga S, et al. (2013b) The PROCESS study: a protocol to evaluate the implementation, mechanisms of effect and context of an intervention to enhance public health centres in Tororo, Uganda. Implementation Science 8: 113.

Chen HT (2005) Practical Program Evaluation. Assessing and Improving Planning, Implementation, and Effectiveness. Thousand Oaks, CA: SAGE.

Coryn CLS, Noakes LA, Westine CD, et al. (2011) A systematic review of theory-driven evaluation practice from 1990 to 2009. American Journal of Evaluation 32: 199-226.

D'Ambruoso L, Abbey M and Hussein J (2005) Please understand when I cry out in pain: women's accounts of maternity services during labour and delivery in Ghana. BMC Public Health 5: 140.

Denzin NK and Lincon YS (2005) Chapter 1. Introduction: the discipline and practice of qualitative research. In: Denzin NK and Lincon YS (eds) The SAGE Handbook of Qualitative Research, 3rd edn. Thousand Oaks, CA: SAGE.

Deyo RA and Inui TS (1980) Dropouts and broken appointments: a literature review and agenda for future research. Medical Care 18: 1146-57.

DiLiberto D, Staedke SG, Nankya F, et al. (in preparation) Designing a complex intervention to improve quality of care for malaria at Ugandan public health centres: an evidence-based and theoreticallygrounded approach.

El Arifeen S, Blum LS, Hoque DM, et al. (2004) Integrated Management of Childhood Illness (IMCI) in Bangladesh: early findings from a cluster-randomised study. Lancet 364: 1595-602.

English M, Schellenberg J and Todd J (2011) Assessing health system interventions: key points when considering the value of randomization. Bulletin of the World Health Organisation 89: 907-12.

Epstein RM, Franks P, Fiscella K, et al. (2005) Measuring patient-centered communication in patientphysician consultations: theoretical and practical issues. Social Science \& Medicine 61: 1516-28.

Fonn S, Mtonga AS, Nkoloma HC, et al. (2001) Health providers' opinions on provider-client relations: results of a multi-country study to test Health Workers for Change. Health Policy and Planning 16(suppl. 1): 19-23.

Glasziou P, Chalmers I, Altman DG, et al. (2010) Taking healthcare interventions from trial to practice. BMJ 341: c3852.

Haaland A, Molyneux CS and Marsh V (2006) Quality information in field research: training manual on practical communication skills for field researchers and project personnel. WHO/TDR. URL: http://whqlibdoc.who.int/hq/2006/TDR_IRM_PCT_05.1_eng.pdf

Haaland A, Sopiene R and Gajauskiene V (2007) Poster describing the method of health communication and management of emotions training, and results of implemeting the method in a TB hospital in Lithuania. International Conference for International Union Against Tuberculosis and Lung Disease. Cape Town, South Africa.

Habicht JP, Victora CG and Vaughan JP (1999) Evaluation designs for adequacy, plausibility and probability of public health programme performance and impact. International Journal of Epidemiology 28: $10-18$.

Hall JA, Epstein AM, DeCiantis ML, et al. (1993) Physicians' liking for their patients: more evidence for the role of affect in medical care. Health Psychology 12: 140-6.

Hawe P, Shiell A and Riley T (2004) Complex interventions: how 'out of control' can a randomised controlled trial be? BMJ 328: 1561-3.

Hudon C, Fortin M, Haggerty JL, et al. (2011) Measuring patients' perceptions of patient-centered care: a systematic review of tools for family medicine. Annals of Family Medicine 9: 155-64. 
Kizito J, Kayendeke M, Nabirye C, et al. (2012) Improving access to health care for malaria in Africa: a review of literature on what attracts patients. Malaria Journal 11: 55.

Knowles M (1998) The Adult Learner: The Definitive Classic in Adult Education and Human Resource Development. Houston, TX: Gulf Publishing.

Kolb D (1984) Experiential Learning: Experience as the Source of Learning and Development. Englewood Cliffs, NJ: Prentice-Hall.

Krasner MS, Epstein RM, Beckman H, et al. (2009) Association of an educational program in mindful communication with burnout, empathy, and attitudes among primary care physicians. Journal of the American Medical Association 302: 1284-93.

Kruijver IP, Kerkstra A, Francke AL, et al. (2000) Evaluation of communication training programs in nursing care: a review of the literature. Patient Education and Counseling 39: 129-45.

Labhardt ND, Cerutti B, Fischer K, et al. (2010) Limited effects on patient awareness with nurse training in interpersonal communication during antenatal care visits - an explorative study from Cameroon. Journal Media and Communication Studies 2: 020-028.

Lewin K (1951) Field Theory in Social Science. London: Social Science Paperbacks.

Lewin SA, Skea ZC, Entwistle V, et al. (2001) Interventions for providers to promote a patient-centred approach in clinical consultations. Cochrane Database of Systematic Reviews: CD003267.

Mann KV (2011) Theoretical perspectives in medical education: past experience and future possibilities. Medical Education 45: 60-8.

Mann KV, Gordon J and MacLeod A (2009) Reflection and reflective practice in health professions education: a systematic review. Advances in Health Sciences Education 14: 595-621.

Mbaruku G and Bergstrom S (1995) Reducing maternal mortality in Kigoma, Tanzania. Health Policy and Planning 10: 71-8.

McPake B (1993) User charges for health services in developing countries: a review of the economic literature. Social Science \& Medicine 36: 1397-405.

Mead N and Bower P (2000) Patient-centredness: a conceptual framework and review of the empirical literature. Social Science \& Medicine 51: 1087-110.

Michie S, Fixsen D, Grimshaw JM, et al. (2009) Specifying and reporting complex behaviour change interventions: the need for a scientific method. Implementation Science 4: 40.

MRC (2008) Developing and Evaluating Complex Interventions: New Guidance. London: Medical Research Council. URL: http://www.mrc.ac.uk/documents/pdf/complex-interventions-guidance/

Oakley A, Strange V, Bonell C, et al. (2006) Process evaluation in randomised controlled trials of complex interventions. BMJ 332: 413-16.

Rowe AK, de Savigny D, Lanata CF, et al. (2005) How can we achieve and maintain high-quality performance of health workers in low-resource settings? Lancet 366: 1026-35.

Schön D (1983) The Reflective Practitioner. San Francisco, CA: Jossey-Bass.

Sitzia J (1999) How valid and reliable are patient satisfaction data? An analysis of 195 studies. International Journal of Quality in Health Care 11: 319-28.

Ssekabira U, Bukirwa H, Hopkins H, et al. (2008) Improved malaria case management after intergrated team-based training of health workers in Uganda. American Journal of Tropical Medicine and Hygiene 79: 826-33.

Staedke SG, Chandler CI, Diliberto D, et al. (2013) The PRIME trial protocol: evaluating the impact of an intervention implemented in public health centres on management of malaria and health outcomes of children using a cluster-randomised design in Tororo, Uganda. Implementation Science 8: 114.

Stewart M (1995) Effective physician-patient communication and health outcomes: a review. CMAJ 152: $1423-33$.

Stewart M (2001) Towards a global definition of patient centred care. BMJ 322: 444-5.

Stewart M, Brown JB, Weston WW, et al. (1995) Patient-Centered Medicine: Transforming the Clinical Method. Thousand Oaks, CA: SAGE.

Stewart M, Meredith L, Ryan BL, et al. (2004) The patient perception of patient-centredness questionnaire (PPPC). Centre for Studies in Family Medicine. Working Paper Series \#04-1.

United Nations (2010) The global strategy for women's and children's health. URL: http://www.un.org/ sg/globalstrategy.shtml 
Van Weel-Baumbarten E (2010) Best evidence teaching communication skills: person centred basic communication skills. Third Geneva Conference on Person-Centered Medicine. Geneva University Hospitals and World Health Organization Headquarters.

Vera H (1993) The client's view of high-quality care in Santiago, Chile. Stud Fam Plann 24: 40-9.

Webster J, Kweku M, Dedzo M, et al. (2010) Evaluating delivery systems: complex evaluations and plausibility inference. American Journal of Tropical Medicine \& Hygiene 82: 672-7.

Weiss CH (1998) Evaluation: Methods for Studying Programs and Policies, 2nd edn. Englewood Cliffs, NJ: Prentice Hall.

Wenger E (1998) Communities of Practice. Learning, Meaning, and Identity. New York: Cambridge University Press.

Williams B (1994) Patient satisfaction: a valid concept? Social Science \& Medicine 38: 509-16.

World Health Organisation (2000) World Health Report 2000. Health systems: Improving performance. Geneva.

World Health Organisation (2005) The World Health Report 2005: make every mother and child count. Wouters AV (1991) Essential national health research in developing countries: health care financing and the quality of care. International Journal of Health Planning and Management 6: 253-71.

Susan Nayiga is a Social Scientist who has participated in numerous evaluations of health-related interventions in Uganda, including coordinating the research of the Process evaluation alongside the PRIME trial. She has interest in evaluating interventions to improve access to better quality health care through high quality social research.

Deborah DiLiberto worked on the design, implementation and analysis of the PRIME trial and parallel Process evaluation. Deborah is currently a doctoral student at LSHTM investigating different methodologies for evaluating complex malaria health service interventions.

Lilian Taaka is a social scientist with extensive field experience in implementing and evaluating health and social interventions, including in the Process evaluation alongside the PRIME trial. She has strong interest in data collection, community work and in interventions which help improve access to better health care and the general well being of people in communities.

Christine Nabirye is a Social Scientist with extensive field experience in a range of evaluations, including the Process evaluation alongside the PRIME trial. She is interested in the role of patient centered approaches in improving the quality of health care.

Ane Haaland is a social scientist who uses qualitative and action research methods to develop models and tools to discover, investigate and solve problems together with users (e.g. a multi-country training model on Patient Centred Care, using reflective and experience based learning). Her research interests are on health provider behaviour change, and visual perception of instructions for use of medicines, with focus on low literate audiences.

Sarah G. Staedke is a Clinical Senior Lecturer at the London School of Hygiene \& Tropical Medicine, but resides primarily in Uganda where she has conducted research on malaria for fifteen years. She was the principal investigator of the PRIME trial and deputy director of the ACT Consortium, an international research collaboration aiming to answer key questions on malaria drug delivery in Africa and Asia.

Clare I. R. Chandler is a Senior Lecturer in Medical Anthropology at LSHTM, and led the social science research across the ACT Consortium, a group of 26 projects testing and evaluating approaches to improving access to and use of artemisinin combination therapy (ACT) antimalarial drugs across Africa and Asia. She designed and led the Process evaluation alongside the PRIME trial. She has developed a strong interest in methodology for interpreting health care interventions and their effects. 